\title{
The use of different types of piston in an HCCI engine: A review
}

\author{
Hassan A. Aljaberi* ${ }^{*}$ A. Aziz Hairuddin and Nuraini Abdul Aziz \\ Department of Mechanical and Manufacturing Engineering, Faculty of Engineering, \\ Universiti Putra Malaysia (UPM), 43400 Serdang, Selangor, Malaysia \\ *Email: hassan.aljabery1976@gmail.com
}

\begin{abstract}
Homogenous charge compression ignition (HCCI) combines the advantages of spark ignition (SI) and compression ignition (CI) engines to improve fuel consumption and emission levels. HCCI engines have the advantage of relatively higher engine efficiency than SI engines while maintaining lower emissions levels than CI engines. Combustion in HCCI engines occurs spontaneously at any location once the fuel-air mixture reaches its chemical activation energy. Pistons have a major effect on controlling the combustion inside the combustion chamber of an HCCI engine. Many researchers have studied various designs for pistons to improve HCCI engines. The aim of this study is to explore these different types of pistons and their designs in terms of improving the performance of HCCI engines fuelled with gasoline. The most common pistons used in HCCI are twostroke pistons, bowl types, specialised pistons, and dome-shaped pistons; each offers distinct advantages and disadvantages. Software simulation is the latest way of determining the best piston to be used for HCCI engines, as it is more cost effective and less time consuming than experiments. Overall, bowl type pistons offer reduced fuel consumption and a higher load capacity when used in an HCCI engine.
\end{abstract}

Keywords: HCCI Engine; gasoline; performance; piston.

\section{INTRODUCTION}

Homogenous Charge Compression Ignition (HCCI) gasoline-based engines are promising innovations in internal combustion engine research. The use of HCCI technology improves engines' performance such as higher combustion efficiency and lower emission levels of NOx and particulate matter [1-3]. These innovations come at the same time as increasing global concern for greenhouse gases leads to demands of automotive industries to manufacture engines with green technology. The drive for improving the efficiency of gasoline-fuelled HCCI engines prompted the automotive industry to create designs that offer optimum engine efficiency. However, various challenges limit the successful operation of HCCI engines. These include controlling the combustion phasing, extending the operating range, and the issue of high unburned hydrocarbon and carbon monoxide emissions [4-7]. Gasoline-based HCCI engines are temporary solutions to the problems of conventional and traditional gasoline engines. They are a high-efficiency technology in terms of engine performance and offer environment-friendly automotive solutions [8]. The challenges of HCCI include vibration, noise, knocking, and limited power output. Vibration and noise are results of the fast burning speeds in combustion HCCI engines since the combustion engines of gasoline-fuelled HCCI are not controlled by sparks but with auto-ignition [9]. The overall 
ensemble of HCCI engines can include different piston designs; these various piston designs contribute to the overall improvement of engine performance [10-13]. Designs are created using numerical simulation to best predict characteristics and outcomes [14]. Today, engine advancements are designed via technological platforms for better and accurate results. The HCCI combustion engine offers potential advancement for engine designs due to high efficiency, low particulate matter emissions, and low nitrogen oxide $[15,16]$. Numerical simulations are commonly used today to achieve greater flexibility in engine designs with lower cost. Models for HCCI engine are now being introduced in the automotive industry. Increased globalisation and the rise in overall mobility have resulted in the demand for a fuel supply for engines that were sustainable and had less discharge of toxic concentrations in the exhaust [17]. Internal combustion engine technology has improved to have better efficiency and fuel economy and be environmentally-friendly. HCCI engines have the capability to use various types of fuel, including gasoline. Models of these engines address the control and operation range extension via the modification of fuel characteristics and advanced control in the mixtures of air and fuel. New models designed through numerical simulations provide optical diagnostics to reveal the in-cylinder combustion process [18]. The stratification process also extends the potential of HCCI operation for higher loads and low-temperature combustion [19].

\section{Advantages and Disadvantages of HCCI Engines}

HCCI has numerous benefits compared to conventional spark ignition and compression ignition. The lean mixture of gas and fuel increases engine efficiency. The ultra-lean premixed gas, compressed by the piston self-ignites at a certain temperature followed by combustion. The HCCI engine uses a high compression ratio, which results in high thermal efficiency. Due to the lean mixture of fuel and air, the maximum temperature is lower than in conventional engines. For a higher load, supercharging or turbocharging is used, which causes the engine to be prone to knocking. This knocking limits the load capability of HCCI engines, which poses a challenge for engine innovation [17]. HCCI also has functional difficulty in oxidising catalysts and turbo-charging because of the fast combustion in lean mixtures and the high compression ratio, which lowers the exhaust temperature [20]. Tables 1 and 2 summarise the advantages and disadvantages of HCCI engines.

Table 1. The advantages of HCCI engine [21, 22].

\begin{tabular}{ll}
\hline No. & \multicolumn{1}{c}{ Description } \\
\hline 1 & Relatively high efficiency at low load conditions \\
2 & Low emissions of particulate matter \\
3 & Ability to use any type of fuel \\
4 & Less maintenance, no spark plug \\
5 & Combustion occurs when the mixture auto-ignites \\
& instantaneously at any location \\
\hline
\end{tabular}

\section{Background of HCCI Engines}

HCCI engines can be typically considered the hybrid of spark ignition and combustion ignition engine designs; these designs contribute their best features to the design of homogeneous compression charge engines. From spark ignition engine design, HCCI engines use mixture homogeneity, while from combustion ignition engine design, HCCI 
engines gain a high compression ratio. Hence, HCCI engines' thermal efficiency is high, and the particulate matter and nitrogen oxide emissions are very low [23]. Moreover, the fuel auto-ignition takes place at several locations in the combustion chambers without the need for any external source of ignition. Incorporating diluted mixtures keeps the increased pressure rates in HCCI engines at an acceptable level due to high levels of combustion [24]. In HCCI gasoline-powered engines, performance can be raised depending on the type of piston present in the engine combustion chamber. Performance enhancements are possible because HCCI engines are under full control of chemical kinetics, making it possible to produce smooth engine operations such as the absence of engine knocking and misfiring $[25,26]$.

Table 2. The disadvantages of HCCI engine [27, 28].

\begin{tabular}{ll}
\hline No. & \multicolumn{1}{c}{ Description } \\
\hline 1 & $\begin{array}{l}\text { Cold start issue, faster engine wear due to high } \\
\text { heat release rate }\end{array}$ \\
2 & $\begin{array}{l}\text { Difficult to control the timing of the auto- } \\
\text { ignition }\end{array}$ \\
3 & $\begin{array}{l}\text { High unburned hydrocarbon and carbon } \\
\text { monoxide }\end{array}$ \\
4 & $\begin{array}{l}\text { Instantaneous pressure rises leads to knocking, } \\
\text { which may cause engine damage }\end{array}$ \\
5 & Limited power output \\
\hline
\end{tabular}

\section{HOMOGENEOUS CHARGE COMPRESSION IGNITION}

Homogenous Charge Compression Ignition is an engine combustion process with a relatively high efficiency. These engines are often called hybrid engines as the ignition process is a mix of conventional spark-ignition and compression ignition technologies $[29,30]$. In an HCCI engine, the fuel is homogenously mixed with air in the combustion chamber. When the piston of the engine reaches TDC, the highest point of the compression stroke, the lean mixture of air and fuel combusts spontaneously even with no spark plug. This auto-ignition occurs when the chemical activation energy has been reached due to the generation of heat [31]. HCCI is a promising alternative engine to traditional and conventional ignition engines. The working principle of an HCCI engine is that it operates with a premixed charge reacting volumetrically along the entire length of the cylinder. It incorporates the best features of conventional compression ignition and spark ignition [29]. Using HCCI in internal combustion engines meets economic demands, conserves energy, and is environmental-friendly. The use of HCCI engines offers the advantages of high thermal efficiency and low cyclic variation at low loads and low equivalence ratios compared to Spark Ignition (SI) engines [32]. Exhaust emissions like carcinogenic $\mathrm{NO}_{\mathrm{x}}$ are reduced by $80 \%$ and smoke by $50 \%$, all while achieving relatively high thermal efficiency [33]. Figure 1 shows the reduced gas emissions of $\mathrm{NO}_{\mathrm{x}}$ in HCCI engines compared to other engines. HCCI offers the added advantage of solving emission challenges in automobiles. The pistons used in HCCI engines are essential for overall performance. Researchers and organisations use many different piston designs to optimise HCCI engine performance [34]. Even when modifying existing piston designs, various computer-based applications are used to make them more compatible with HCCI 
engines. Using software allows researchers to predict engine performance under various hypothetical conditions.
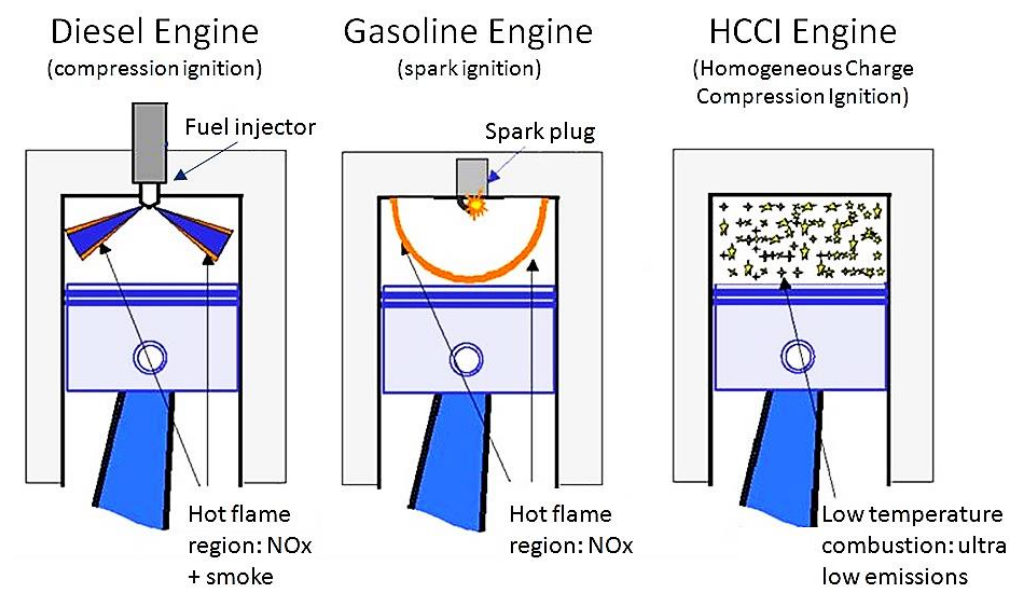

Figure 1. Gas emissions in different engines [16].

\section{INTRODUCTION TO PISTONS}

Pistons are a group of engine ensembles made of cylindrical metal that exhibits vertical movement within the cylinder. Pistons are used in various machines, like pneumatic and gas compressors, pumps, and reciprocating engines. The main function of a piston in a machine is to transfer force from the gas expanding in the cylinder to the crankshaft with the help of pistons or connecting rods. Pistons are designed at the movable end of the combustion chambers. They are made of an alloy of cast aluminium due to its lighter weight and improved thermal conductivity. Aluminium's expandability is better with heat, which allows for better movement of pistons within the cylinder bore due to increased clearance. However, clearance must be within limits, as excess clearance because of increased noise leads to lower compressed rates. Similarly, pistons with low clearance can lead to seizing of pistons with the cylinder. A piston comprises a piston pin, piston pin bore, piston rings, the ring grooves, and the ring lands. Figure 2 shows the various parts of a piston. The piston heads at the upper surface are subjected to increased heat and force during the operation of the engines [35].

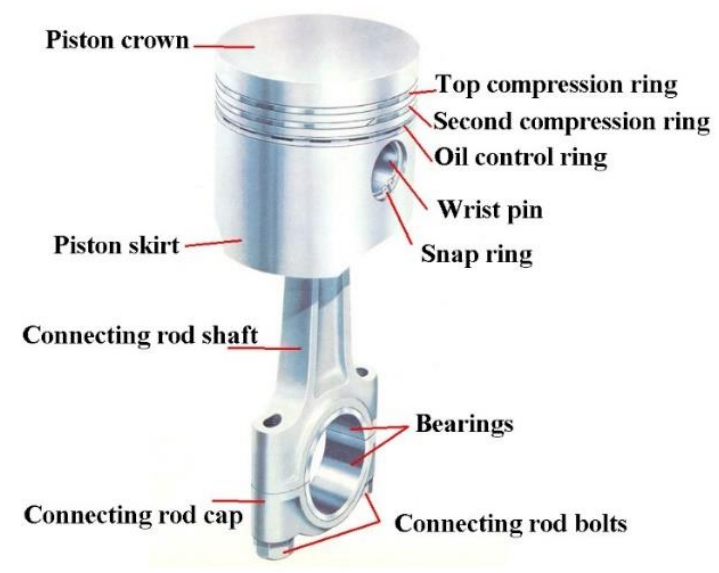

Figure 2. Parts of the piston [36]. 
The piston is the part of the engine located in the cylinder bore that moves up and down between Top Dead Centre (TDC) and Bottom Dead Centre (BDC). Technically, its function is to transfer force to the crankshaft via a connecting rod [37]. Proper clearance should be maintained because excess clearance increases noise and lowers the compression rate, while low clearance causes seizing of the piston to the cylinder [38]. The piston head in the upper surface part is subject to heat and force during normal engine operations [36]. The principle of efficient piston design includes the capability to overcome structure failure, noisiness, and skirt scuffing. Pistons should be designed so that they do not contribute to high friction, which causes reduced engine performance. Apart from that, the profile of the piston cavity and the nozzle are also the important determinants of good piston design [39]. Furthermore, the crown of the piston and the incylinder air charge are important parameters that affect engine performance.

There are three principle classifications of pistons; dome, flat, and bowl. Dome pistons have a dome shape and differ from flat-top pistons in the sense that they lack a flat top. This results in extra volume at the top compared to flat-top pistons; this extra volume results in an increase in the compression ratio, which in turn results in performance improvement. There is a disadvantage with the dome shape as well. Pistons that have high domes slow down burning depending on the combustion chamber shape in the head [40]. Flat-top pistons have flat tops, as the name suggests, and are used for engines that are mass produced. Because of their simple designs, the cost to manufacture a flat top piston is also low, resulting in reduced engine costs [41]. Bowl pistons are mainly used in engines to reduce the compression ratio because of their shape, which adds to the total combustion volume. Because of their purpose of reducing the compression ratio, these pistons are perfect for super-charged and turbo-charged engines [42, 43]. The most common pistons in HCCI engines are bowl types, two-stroke pistons, dome-shaped pistons, and specialised pistons, each of which offers distinct advantages and disadvantages [44]. The advantage of bowl type pistons is that they can be used in a supercharged engine to avoid spark knock with the set conditions; a disadvantage of these is that, due to the hotter running piston, there is an increase in production of harmful gases like nitrogen oxides. The two-stroke piston offers a variety of advantages: it is lighter, compact, and less costly. It helps in generating a significant power boost; however, it offers the same disadvantage in that the oily smoke it emits is a source of pollution. In contrast to the previous two pistons, domed-shaped pistons stay in compression under loads, push the incoming mixture to the top of the cylinder, and prevent short circuits [45]. One of the disadvantages is that, due to combustion, pressure forces the center of the dome downwards, which distorts the top ring groove.

\section{DIFFERENT TYPES OF PISTONS DESIGN AS USED IN HCCI ENGINES}

The design of pistons is important for engine performance. Pistons must have low friction to improve engine performance and fuel economy [46]. The profile of the piston cavity and the configuration of the nozzle also play significant roles in engine combustion, fuel emission, and the fuel consumption. The design of the piston cavity, nozzle design, piston bowl type, and the in-cylinder charge air are all important parameters that affect engine performance. The geometry of the piston cavity and various dimensions such as the pipe region, torus radius, impingement area, and the cavity lip area, affect the formation of emissions in engine combustion. Research has shown that combustion chambers with optimal shapes help reduce emissions during engine combustion [47]. Emissions are reduced by altering the piston cavity geometry: the dimensions of pipe, radius, and cavity 
lip area. Piston skirt design is also important in the control of friction performance for engines where proper management of the piston's vertical movement reduces friction [35]. The design of piston cavity shapes plays a defining role in the motion of air, fuel mixing, combustion, and emissions. Some designs are more suitable to minimising combustion engine noise, some produce more displacement, while others are known for having more efficient combustion rates [48]. As such, the piston cavity geometry influences emission formation. The performance of piston crowns is evaluated by considering cylinder pressure, the vibration rate of the engine, and acoustic sound pressure, which is measured at a distance of one meter from the engine. Their efficiencies can be maximised by increasing the compression ratio and adopting a faster combustion rate [24]. In this regard, piston shapes and designs can assist in establishing optimum performance with less emissions and fuel consumption. As noted above, there are three common types of piston designs used in HCCI gasoline-fuelled engines; flat, bowl, and dome. The choice of design depends on the desires of the manufacturer [44]. Therefore, there is a need to understand in-cylinder fluid dynamics, since it has been noted to be unsteady, three-dimensional, and turbulent. High-quality mesh and the use of an appropriate valve lift profile are some aspects associated with a predictable flow structure [4]. The design of engine components such as pistons and combustion chambers, contribute to the general efficiency of HCCI engines. Vressner et al. [49] found that the geometry of the combustion chamber, which includes the piston design and parameters, affects the rate of heat release in HCCI engines. The combustion of HCCI engines has load limitations during fast combustion and high peak pressures.

\section{Square Bowl Piston Design}

As its name suggests, this piston is a modified version of the bowl piston. It has a square bowl space on its top as shown in Figure 3. This shape has a direct influence on the rate of heat released, especially with HCCI engines [48]. As a matter of concern, most HCCI combustion is limited to load as a result of high pressure and fast combustion; thus, the speed of combustion can reduce the load range. Therefore, square bowl pistons produce micro-turbulence derived from rounded corners, which account for the superior air-fuel mixing [48].
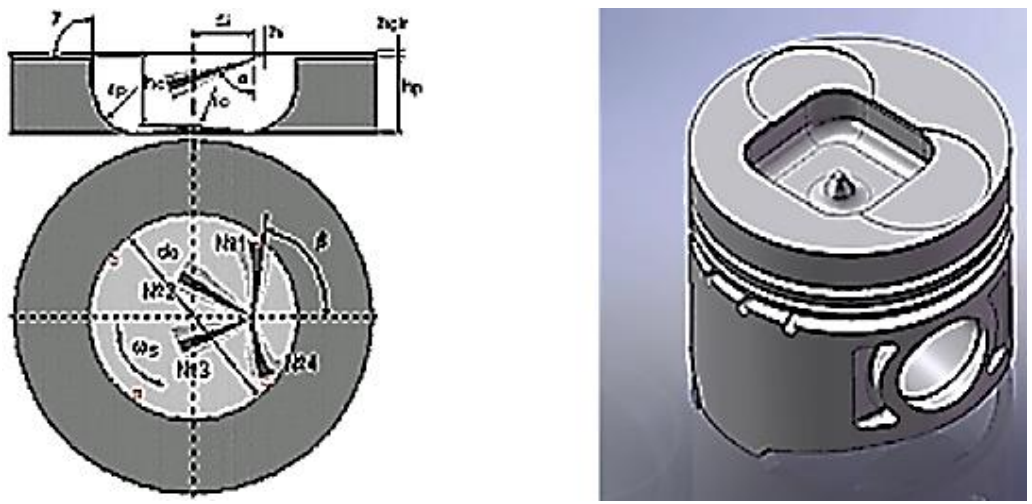

Figure 3. Square bowl piston design [48].

The use of a bowl-shaped combustion chamber decreases rate of heat release by about 50\% compared with a disc-shaped combustion chamber [38]. In effect, the bowlshaped geometries of the chambers offer higher load capacities, along with an acceptable rise in pressure rates [50]. The piston geometry in a square bowl combustion chamber 
with narrow squish regions causes turbulent conditions, since the gas is forced down into the bowl. Chemical kinetics plays a huge role in square bowl pistons too; it is defined as the rate at which chemical reactions occur. This direct effect of geometry on turbulence conditions in HCCI engines greatly affects chemical kinetics during combustion. A model via CFD using detailed chemical kinetics predicts that bowl-type pistons increase the combustion duration due to increases in wall heat transfer [48].

An HCCI with square bowl chamber shown in Figure 3 breaks up the flow in smaller eddies along the corners to generate high amounts of small-scale turbulence. In this design, the piston crowns are interchangeable and have an extra piston ring to gain top land height for greater combustion efficiency [48]. There is a tendency towards high turbulence in pistons and chamber designs with square geometry, resulting in longer burn duration. There is a thicker boundary layer resulting in broader temperature distribution. In effect, there is a lengthened combustion period, since the cold mass inside the cylinder takes the longest time to reach its ignition temperature during the compression of burned gasses [51].

\section{Bowl Piston Design}

Bowl pistons are applied to minimise compression ratios due to the additional bowl combustion volume. They can be used on supercharged or turbocharged engines to eliminate detonation (that is the spark knock) under the boosted conditions of the two designs. Bowl pistons have compact combustion chambers and fast combustion rates [48]. Figure 4 shows a sample bowl piston used in a diesel engine, in which the bowl is utilised to confine the gasoline spray for good and fast combustion. The same does take place with a spark ignition engine, as faster burning is characterised by a compact combustion chamber [52]. Piston bowl configuration influences in-cylinder mixing in HCCI combustion engines. It also contributes to the formation of pollutants during the engine combustion process. The combination of bowl geometry, swirling, and spray targeting helps reduce emissions and increase the efficiency of fuel consumption [53]. Furthermore, a combustion chamber with a bowl-in-piston configuration has a decreased ratio of areato-volume in engines with only small displacements. The squish areas increase the layer of boundary volume. There must be sufficient space in the bowl to maximise the bulk volume [54].
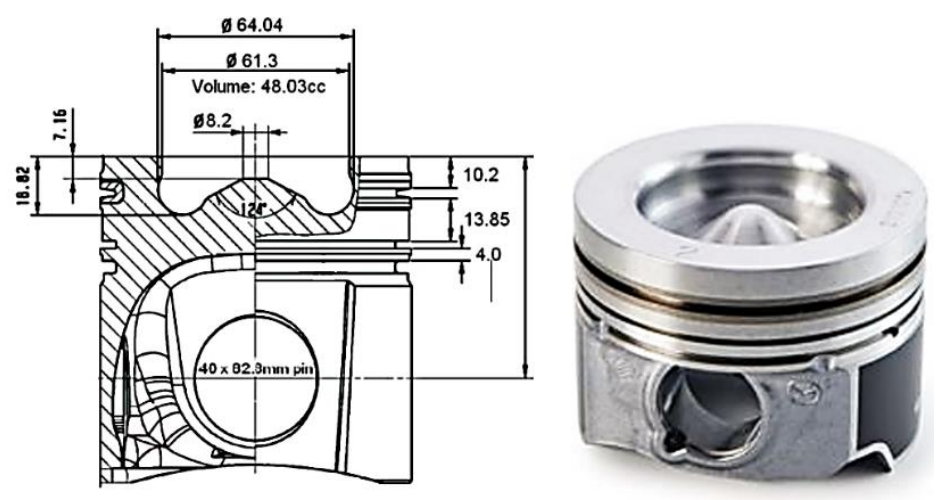

Figure 4. Bowl piston design [52].

The piston bowl is commonly utilised in gasoline engines. HCCI engines do not have an ignition phase so that the piston crowns may form the combustion chamber [52]. Such engines use pistons with differently shaped crowns; as direct injection is becoming 
popular, gasoline engines may also use the same types of pistons. The shapes of the piston bowl usually manage the movement of the air and fuel as pistons move up during a compression stroke. The fuel and air swirl into a vortex before combustion take place, thus creating better combustion [11]. By influencing the fuel or air mixture, one can achieve better and more efficient combustion. Therefore, it is important to emphasise that bowl pistons do have different shapes that are commonly designed to reduce fuel consumption. With the help of direct injection (DI), bowl type pistons are becoming more popular.

\section{Dome Piston Design}

The dome piston has additional volume on the top compared to flat pistons, whose tops are flat as shown in Figure 5. The extra volume is for improving the compression ratio of the piston and, consequently, improving performance. However, inefficiency in the incylinder surface design and highly domed pistons cause inefficient combustion and slow burning rates of the air-fuel mixture [21]. Convexity is used to develop and improve optimum chamber shape with a high compression ratio and efficient combustion rate.

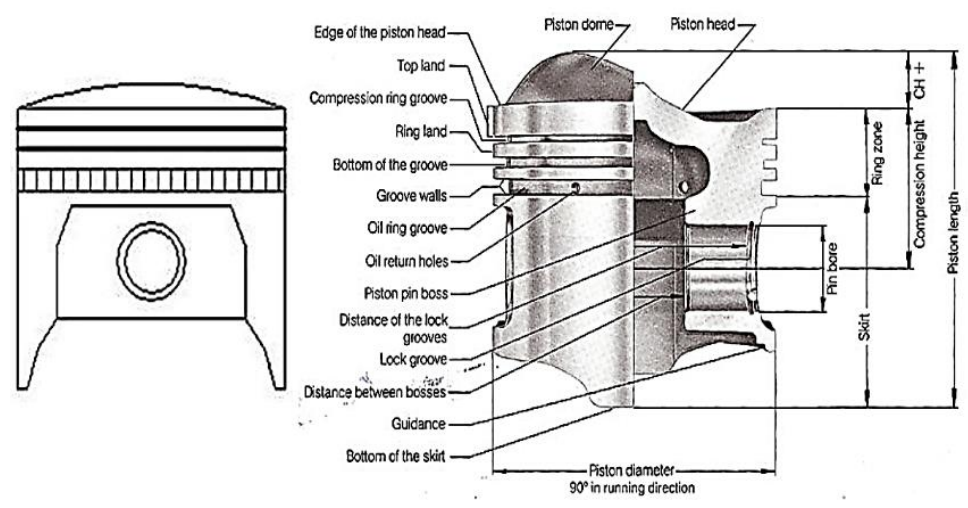

Figure 5. Dome piston design [21].

In HCCI applications, the bowl-dome piston geometry has a significant role in the prepared mixture and the following combustion process. It also affects the characteristics of emissions due to late injection in HCCI, especially when liquid impingements occur. Kashdan et al. [55] revealed the effects of the types of the piston via Planar LIF 355 imaging. They found that the use of dome shape or flat pistons allowed spatial and temporal detection of the precursors of autoignition before chemiluminescence, which is the emission of light but not excessive heat during the chemical reaction. Thus, piston geometry affects distribution and combustion in HCCI engines.

\section{Flat-Top Piston Design}

Figure 6 shows the flat-top piston. This piston is commonly used in mass-produced engines. They are easy to develop, which keeps the cost of the engines low. Some flattop pistons have material extracted from the top to ensure the valves do not hit the pistons during the opening and closing of the intake and exhaust valves. This improves their compression ratios by allowing the pistons to rise higher into the head of the cylinders [56]. The last decade has seen advancements in piston technology. Zheng et al. [52] suggested that adding silicone to aluminium will decrease piston expansion caused by heat present within the engine. Thermal expansion reduces piston seizure. Silicone also increases the strength of the aluminium and reduces wear [52]. The flat-top piston has 
several merits, including less surface area, so it is lighter with a shorter, faster heat path to the cylinder wall. In addition, the piston crown is in tension under load, the valves close fast, the opening is not masked by a chamfer, the piston shape does not affect the entry and exit angles of the valves, and the combustion chamber is a true hemisphere.

Flat-top pistons can be used in HCCI engines. Flat-top pistons are easier to manufacture. Some flat-top pistons have a valve space, where a small amount of material on the top has been removed to give space for valves' movements. A higher compression ratio can be used when this type of piston design is used in any engines [52].
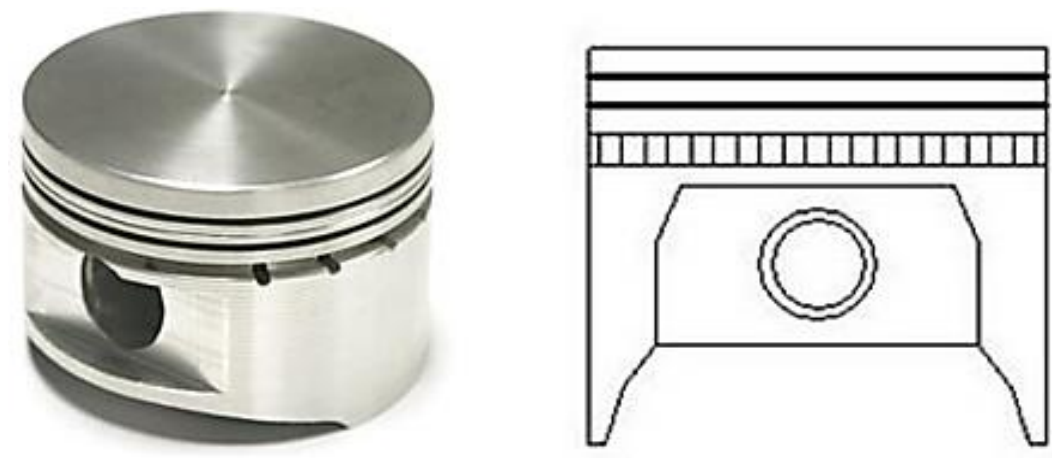

Figure 6. Flat-top piston design [52].

Pedersen and Schramm [38] evaluated seven shapes of pistons designed for HCCI engines and revealed that flat-top piston crowns produce good results. Regarding the shapes of piston crowns' abilities to reduce knock and transmission of combustion noise to the HCCI engines, the researchers found that the combustion knock was suppressed by limiting the size of the combustion volume. This process was done through the splitting of the compression volume into four small volumes placed between the cylinder liner and the piston. As a result, the use of a flat piston crown increased noise due to the resonance between the four volumes. Noise was reduced when using eight volumes with another piston crown and the cylinder liner not directly exposed to the combustion. Another configuration using seven hemispherical volumes also decreased noise. The design with bowl-type pistons created the most silent and consistent noise in HCCI engines [38]. Noise and vibration caused by the autoignition feature of gasoline-fuelled HCCI engines cause faster-burning speeds during combustion. To address this challenge, the local mixture that occurs in the combustion chamber must be varied via the stratification of temperature. Parameters that contribute to this include flow motion, heat transfer effects, and turbulence. Piston motion and swirling help derive the calculations for the stratification for the fuel, in which stratification fuel is injected into the cylinder before ignition, which is vital for combustion duration extension [9].

\section{Two-Stroke Engine Piston}

Two-stroke pistons (Figure 7) are preferably used due to their strong thermal and mechanical loads. Their design principle is based on two-strokes engines. Two-stroke pistons are mostly used in HCCI engines for better performance. Better intake and exhaust processes occur when using two-stroke pistons, thus offering higher functionality and reliability [57]. In a two-stroke HCCI engine, a flat-top piston can also be used. The combustion chambers' steep roofs yield greater clearance volume, creating a lower compression ratio when using a flat piston. This choice of piston design reduces the compression ratio to a minimum of about 9:1. The types of pistons used in HCCI engines 
have alternated from two-stroke to four-stroke conformations with various fuels, including diesel, gasoline, hydrogen, methanol, and natural gas [58].

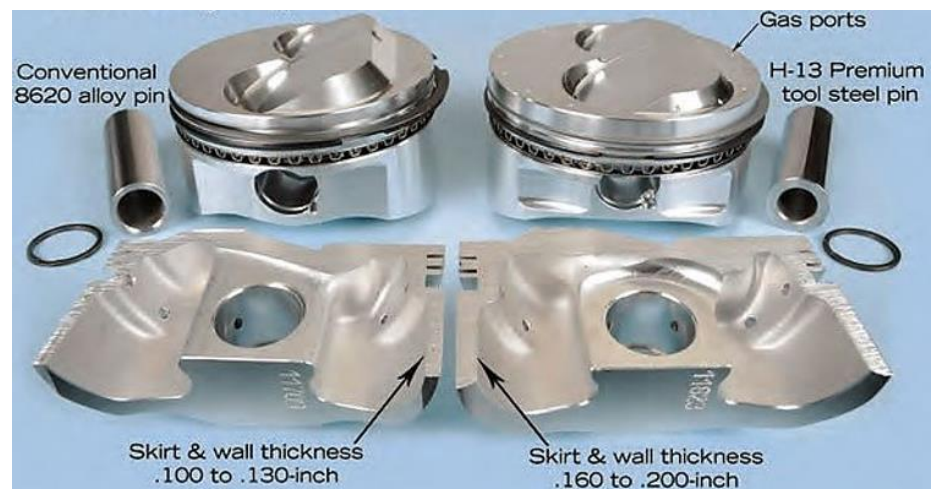

Figure 7. Two-stroke piston [57].

\section{Four-Stroke Engine Pistons}

In a four-stroke HCCI engine (Figure 8), Osborne [59] used the Ricardo direct-injection design for the pistons where there is a large bowl piston crown purposely designed for engines with stratified charges. This piston design with a bowl on top is important in directing the fuel going to the piston during late injection timings. Furthermore, the crown piston is slightly raised for the increased compression ratios that are typical for gasolinebased HCCI engines. For gasoline-based HCCI engines, higher compression ratios become useful in overcoming the disadvantages caused by the reduction of firing frequency compared to engines with two-stroke [60].

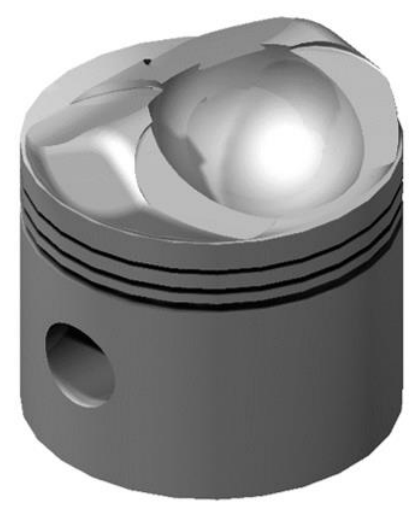

Figure 8. Four-stroke piston [59].

Considering past use in two-stroke engines, Ghorbanpour and Rasekhi [25] broadened their use to four-stroke engines and endeavored to increase basic scientific knowledge of HCCI combustion engines. They were the first to consider HCCI ignition in four-stroke gasoline engines. They perceived that HCCI was administered by compound energy, with slight impacts of instability and blending. They led studies using primary reference fuels (PRF) and admission preheating. Using a heat discharge evaluation and cycle model, they focused on the HCCI combustion procedure and managed a reduced temperature (less than $676{ }^{\circ} \mathrm{C}$ ) hydrocarbon oxidation energy. Additionally, they presumed that HCCI ignition is a chemical combustion influenced by force, temperature, and mixtures of the in-cylinder charge [25]. Zhang et al. [61] studied 
a four-stroke HCCI engine using gasoline. In the four-stroke scenario, various studies have involved reviewing HCCI ignition using different pistons. Table 3 summarises the functions and advantages of the different types of pistons discussed so far.

Table 3. Summary of the functions and advantages of different piston designs.

\begin{tabular}{|c|c|c|}
\hline Piton design type & Function & Advantage \\
\hline $\begin{array}{l}\text { Square bowl piston } \\
\text { design }\end{array}$ & $\begin{array}{l}\text { Produces micro-turbulence } \\
\text { derived from its rounded } \\
\text { corners, which accounts for } \\
\text { the superior air-fuel mixing. }\end{array}$ & $\begin{array}{l}\text { - The use of a bowl-shaped } \\
\text { combustion chamber } \\
\text { decreases the heat release } \\
\text { rate by about } 50 \% \text { compard } \\
\text { with a disc-shaped } \\
\text { combustion chamber. } \\
\text {-Offers higher load } \\
\text { capacities along with an } \\
\text { acceptable rise in pressure } \\
\text { rates. }\end{array}$ \\
\hline Bowl piston design & $\begin{array}{l}\text { Bowl pistons are applied to } \\
\text { minimise the compression } \\
\text { ratio due to the additional } \\
\text { bowl combustion volume. }\end{array}$ & $\begin{array}{l}\text {-Fast combustion rates. } \\
\text {-Reduced fuel consumption. }\end{array}$ \\
\hline Dome piston design & $\begin{array}{l}\text { Commonly used in mass- } \\
\text { produced engines with dome } \\
\text { on top instead of flat surface. }\end{array}$ & -Improved compression ratio. \\
\hline Flat-top piston design & $\begin{array}{l}\text { Commonly used in mass- } \\
\text { produced engines. }\end{array}$ & $\begin{array}{l}\text {-Reduced cost of the engine. } \\
\text {-Easier to manufacture. } \\
\text {-Higher compression ratio. }\end{array}$ \\
\hline
\end{tabular}

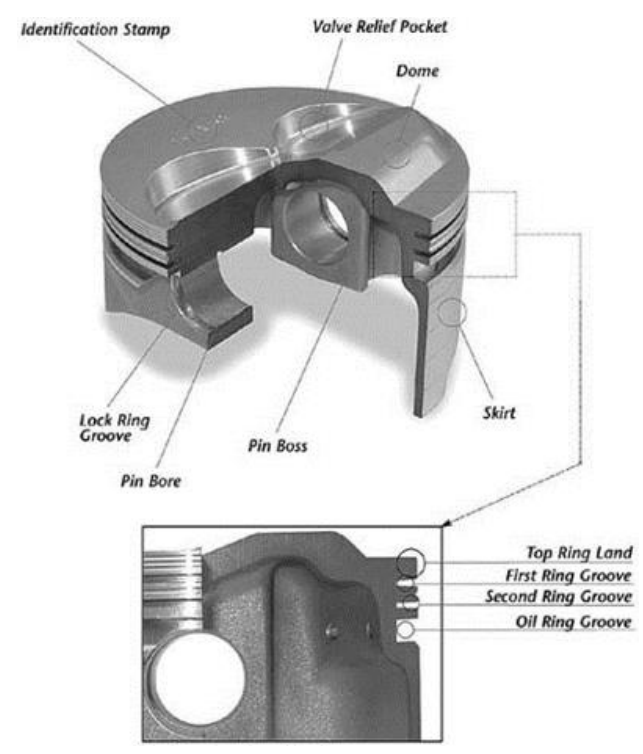

Figure 9. Skirt piston [62].

\section{Other Specialised Piston Designs}

There are many specialised pistons such as the cast solid skirt pistons and the forged solid pistons that can be used in HCCI gasoline engines (Figure 9). Cast solid skirt pistons are very distinguishable and operate with long lives and economic value. These pistons have 
robust parts such as the piston crowns, skirt, and the ring zone. These pistons can be used for engines that are small or those requiring large capacities [63]. Forged solid skirt pistons offer increased strength. There have smaller wall cross-section requirements and the weights of the pistons are lower. These pistons are meant for heavy duty loads such as in racing cars [62].

\section{Design Considerations for Pistons}

Effective piston design for HCCI engines includes overcoming structure failure, noisiness, and skirt scuffing. Pistons should be designed to not contribute to high friction for the engine, as that could lead to increased fuel consumption, thus reducing the performance of the HCCI engines. Additionally, the profiles of the piston cavities and nozzles are also important determinants of good piston design. Furthermore, the piston bowl types and the cylinder air motion charge also impact overall engine performance [35]. Various considerations are of importance for piston design, including the geometry of the piston cavity, dimensions of the pipe region, torus radius, impingement area, and the cavity lip area. These all influence the combustion properties of emission engines. Maintaining an optimum shape of the combustion chamber allows for reduced emissions. The so-called piston skirt design is important to reduce the chances of friction; therefore, proper control of pistons' vertical movements remains essential. This helps to address the overall issues of friction related to the movement of the pistons [35]. Decreasing mechanical friction leads to improved engine efficiency. The major sources of friction are the piston skirt and cylinder. These two components are affected by certain parameters: total clearance, piston tilt, design of piston skirt, and overall surface roughness. The primary sources attributed to friction remain the piston skirt friction, movement of the bearings, and the piston rings.

The designs of the piston skirt and rings are essential for overall engine efficacy [64]. The piston ring packs are very important, as they contribute to the engine's fuel consumption. Thus, optimising ring pack design, like radial collapse, drainage holes, and reverse flutters, contributes to improved performance of the piston ring pack by reducing friction losses and the amount of fuel consumed by the engine [14]. The automobile industry is stressing the improvement of piston designs to improve the efficacy of gasoline- and diesel-based engines. Together with improved piston design, the industry is striving to improve the performance of engines in a cost-effective manner and also be environmentally-friendly in terms of toxic emissions [65]. Thus, the choice of pistons used in various formats of the engine must contribute to efficiency and durability. Pistons are the major contributers to losses in efficiency: around 50-60\% loss in the mechanical efficiency of engines [66]. Especially for HCCI engines, it has been observed that the combustion process heats up the piston crown; the thermal impact must be dissipated through the rings and piston skirts. Hence, aluminium-based pistons are recommended for these engines, as they have greater dissipative power. Since the coefficient of linear expansion for aluminium is high, necessary clearance allowance must be considered while designing the engine [46]. Gasoline-based engines are also operated with intrinsic qualities and properties of thermal conditions in the cylinder. Deposits are regularly checked in the combustion chambers due to the fuel's higher burn rates. In compound piston engines, the skirt and crown are constructed of different materials; these run at medium speed and burn outstanding fuel. These crowns achieve a temperature of $450{ }^{\circ} \mathrm{C}$ and, within this region there is a need for least bending and high quality, keeping in mind the end goal to protect from gas stacks and maintain the rings in connection to the liner. Heat must stream uniformly away from the crown; generally warm mutilation will cause 
a non-round cylinder, bringing about decreased running leeway or even conceivable contact with the liner divider. Besides this problem with heat, they are also subject to pressure problems from burning and pressure loads, as well as inertial burdens.

\section{EFFECTS OF DIFFERENT PISTON DESIGNS ON HCCI ENGINES PERFORMANCE}

The choice of pistons for the engine ensemble is vital, as the reciprocating motion of the pistons contributes to the efficiency and durability of the engine. The aluminium-based piston is highly recommended for engines like HCCI engines due to the high diffusivity effect of the material. However, there is required clearance for the use of aluminium pistons due to high coefficient linear expansion [47, 52, 67]. The operating range of gasoline-based HCCI engines can also be extended through an understanding of cylinder thermal conditions. One way of understanding these thermal conditions is by checking the deposits in the combustion chamber due to impacts on the near wall, as well as the burn rates [68]. Güralp et al. [69] investigated the effects of piston design on the performance of HCCI engines. In their research, they used a single-cylinder engine in which thermocouples were attached to piston tops and the surface of cylinder heads. The changes in the phasing of peak temperature were correlated with the presence and tracking of deposit thickness in the combustion chamber. Their results provided insights into the metal interface on the cylinder head and the piston top, as well as the impact of the deposits [69]. Various piston crown geometries have various effects on the acoustic resonance that occurs inside the combustion chamber. Each design contributes differently to reductions in noise emitted from the engine. Embedded piston crowns with cavities reduced noise more those with cavities formed between the cylinder liner and piston [38].

An HCCI gasoline engine can be represented via computer simulations that show the network of the resistance networks, including the cylinder head, cylinder liners, and the pistons as shown in Figure 10 below. The piston serves as the thermal junction where the transfer of heat occurs from the oil-cooled surface to the piston skirt [70]. Thermal contact resistance between the liner and piston skirt is assumed [71].

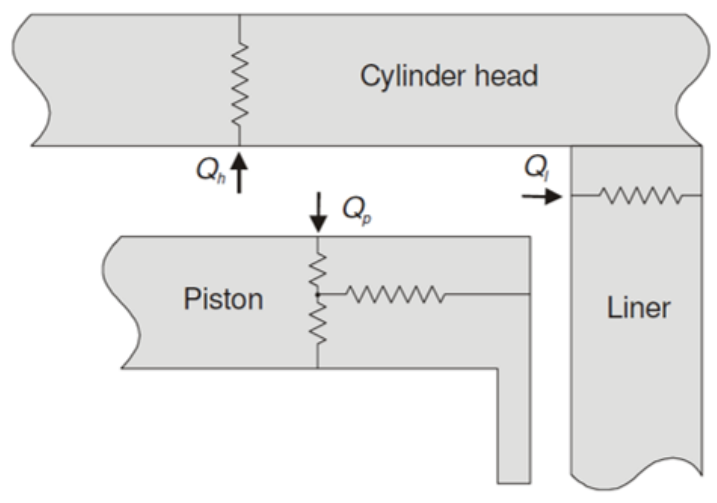

Figure 10. Simplified thermal resistance network [71].

Piston design has significant effects on HCCI engines fuelled with gasoline. Aceves et al. [72] analysed the effects of piston crevices' geometry on HCCI engines during the combustion and emission processes. In the study, three pistons with varying sizes were used in the analysis while maintaining a constant compression ratio. The effect of the piston crevice sizes on the combustion of HCCI was predicted where the results were compared. Different tests were done with varying sizes of piston creviced via build-up of 
removable piston crowns. The piston crowns were changed to vary the size of the pistons while keeping the compression rate constant. In a single cylinder part of a Volvo multicylinder heavy-duty truck engine, various piston designs were tested. Figure 11 shows the geometry of a cylinder with removable crowns with different heights and widths, while keeping the compression rate constant (17:1).

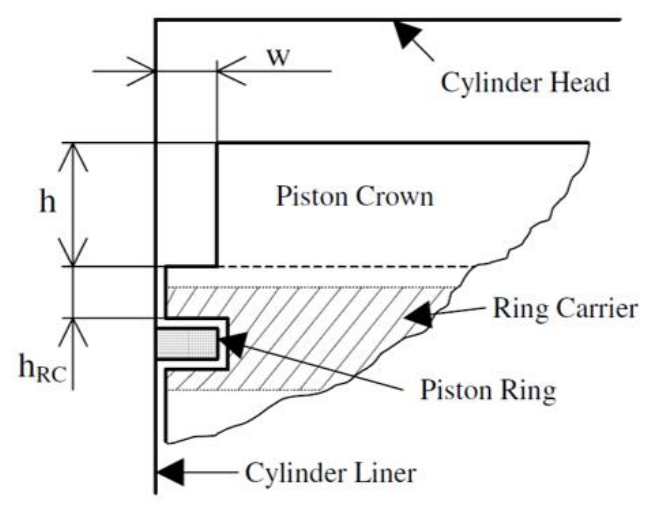

Figure 11. The geometry of the cylinder with removable crowns and different combinations of crown height (h) and crevice width (w) [72].

There were three crowns used with the dimensions found in Table 4 [72]. Figure 11 illustrates piston dimension nomenclature. $\mathrm{V}_{\text {comp }}$ is the volume of the combustion chamber at TDC $\left(100 \mathrm{~cm}^{3}\right)$. The effects of piston geometry on HCCI engines fuelled by gasoline (iso-octane) using crevice sizes of $0.26,1.3$, and $2.1 \mathrm{~mm}$ were significant. The results were used in numerical models to predict piston geometry effects on HCCI engines. Based on the results, piston crevices that are wide $(1.3 \mathrm{~mm}$ and $2.1 \mathrm{~mm})$ do not decrease hydrocarbon emissions. Pistons with $0.26 \mathrm{~mm}$ crevice width decrease hydrocarbon emissions as the air/fuel ratio increases. Also, using same-width crevice pistons, the mass found in crevices burned at the richest mixture only. Lean mixtures did not initiate burning, thereby increasing $\mathrm{HC}$ emissions. The results shown in the multilevel zone could be used to predict the crevice geometry of pistons in HCCI engines. These results contribute to the design of HCCI engines with low emissions, low peak pressure in the cylinder, and optimum efficiency [72].

Table 4. Crevice dimensions.

\begin{tabular}{llll}
\hline Piston & $\begin{array}{l}0.26 \mathrm{~mm} \\
\text { crevice }\end{array}$ & $\begin{array}{l}1.3 \mathrm{~mm} \\
\text { Crevice }\end{array}$ & $\begin{array}{l}2.1 \mathrm{~mm} \\
\text { crevice }\end{array}$ \\
\hline Topland width, w, mm & 0.26 & 1.3 & 2.1 \\
Topland height, h, mm & 24.5 & 25.3 & 26.0 \\
Topland volume, cc & 2.7 & 12.5 & 20.8 \\
$\mathrm{~V}_{\text {topland }} / \mathrm{V}_{\text {comp }}$ & 0.027 & 0.125 & 0.208 \\
\hline
\end{tabular}

Hyvönen et al. [73] studied piston design for better HCCI gasoline-fuelled engines through Variable Compression Ratio (VCR). A test engine was used to compare the effect of VCR through the use of two pistons, changing the original values of $8: 1$ and 14:1 to 9:1 and 21:1. Two pistons, P17 and P21, were compared regarding their effects on engine performance [56]. Figure 12 shows these two tested pistons. 


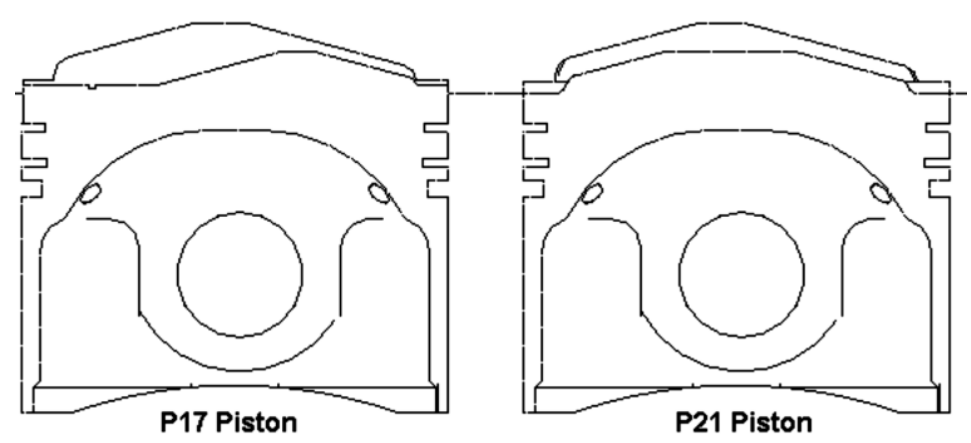

Figure 12. Combustion chamber comparison between P17 and P21 pistons [56].

The two pistons vary. Primarily, these pistons resulted in different compression ratios. The shape of the P17 piston was designed to allow exhaust cam phasing. The compression volume for such a piston is on the side of the exhaust valve. The volume is on the narrow side of the inlet valve. This design is expected to affect heat losses. P21 was specifically made with exhaust valve pockets. The compression volume is more distributed in the combustion chamber. There were expected minor heat losses compared with the P17 piston. The test fuel for the engine was gasoline. The shapes of the various combustion chambers were changed, thus increasing the maximum compression ratio from 17:1 to 21:1. There was less heat loss in P21 due to even distribution at the walls of the combustion chambers. The P17 chamber, with a ratio of $1.9 \mathrm{~mm}$ volume to area, required a higher-octane number than did the other. There was higher combustion efficiency with the P21 piston at low load points. With the P21 chamber, the compression ratio was higher, at 4.5 bar. Even when the lowest load point share was considered, the compression ratio of P21 was still higher, causing the combustion phasing to be earlier, thus increasing combustion efficiency. When the operating range of the pistons was tested, it was found that the compression ratio reached a maximum at $200 \mathrm{rpm}$. In the P21 piston, the maximum compression ratio was achieved at $500 \mathrm{rpm}$. VCR use for engines results in robust combustion initiation [73].

\section{CONCLUSIONS}

This literature review presented some issues related to the effects of different piston crown designs in one HCCI engine. The direction of the piston is crucial to overall engine performance and efficiency. Innovations in engine technology employ designs that drive better performance for HCCI engines. Piston design is important for the best engine performance. Researchers strive to achieve successful piston design for HCCI gasolinebased combustion engines to eliminate various failure modes, such as structure failure, unusual noise, and skirt scuffing. Pistons play an especially crucial role in engines. The designs and geometry of pistons contribute to overall engine performance. In the same manner, piston geometry plays a vital role in Homogenous Charge Compression Ignition engine performance. With an optimum design of pistons, there is controlled turbulence generation, thereby reducing the combustion rate. Also, the geometry of the combustion chamber that includes the pistons affects the rate of heat release of HCCI engines. Pistons must deliver the least friction for the engine to improve engine performance and fuel economy. Types of pistons include:

- Flat pistons showed higher turbulent kinetic energy (TKE) compared with center bowl pistons. 
- Flat pistons enhanced air movement in the cylinder space more than did bowl pistons.

- Bowl pistons produced the highest level of TKE.

- Bowl pistons had $15 \%$ more tumble ratio compared to flat pistons.

- These design aspects significantly reduced emission levels.

Dynamic analysis for engines can be used by various industries to predict engine behaviours and achieve the best performing engine. The common pistons used in HCCI engines are bowl types, two-stroke pistons, dome-shaped pistons, and specialised pistons, each of which offers distinct advantages and disadvantages. However, the quest for ideal piston design should be continued through software simulations to reduce high friction on engines as friction leads to increased consumption of fuel, thus reducing the performance of HCCI engines. Different piston types have different advantages and limitations. While the square bowl design reduces heat release and offers higher load capacities, the bowl piston design offers faster combustion rates and reduces fuel consumption. The dome piston design improves the compression ratio, while the flat-top design reduces engine cost, as it is easier to manufacture and has a higher compression ratio. Due to its efficient design, better and more efficient combustion, and availability in different shapes to reduce fuel consumption, the bowl piston is the recommended piston to be used in HCCI engines.

\section{ACKNOWLEDGMENTS}

The authors would like to be obliged to Universiti Putra Malaysia (UPM) for providing laboratory facilities and financial assistance under project no. GP-IPS 9486700. The author also thanks, M.M. Noor for comments and discussions.

\section{REFERENCES}

[1] Contino F, Foucher F, Dagaut P, Lucchini T, D’Errico G, Mounaïm-Rousselle C. Experimental and numerical analysis of nitric oxide effect on the ignition of isooctane in a single cylinder HCCI engine. Combustion and Flame. 2013;160:147683.

[2] Nemati A, Khalilarya S, Jafarmadar S, Khatamnejhad H, Fathi V. Numerical parametric investigation of a gasoline fuelled partially-premixed compressionignition engine. Journal homepage: www IJEE IEEFoundation org. 2011;2:73948.

[3] Hairuddin AA, Wandel AP, Yusaf T. An introduction to a homogeneous charge compression ignition engine. Journal of Mechanical Engineering and Sciences. 2014; 7:1042-52.

[4] Hairuddin AA, Yusaf T, Wandel AP. Single-zone zero-dimensional model study for diesel-fuelled homogeneous charge compression ignition (HCCI) engines using Cantera. International Journal of Automotive and Mechanical Engineering. 2016;13(2):3309-28.

[5] Hasan MM, Rahman MM, Kadirgama K. A Review on Homogeneous Charge Compression Ignition Engine Performance Using Biodiesel-Diesel Blend as a Fuel. International Journal of Automotive and Mechanical Engineering. 2015;11:2199-211.

[6] A. Aziz AR. Investigation of Auto-Ignition of Octane-Cng Mixture in Hcci Engine. International Journal of Automotive and Mechanical Engineering. 2015;11:2235-42. 
[7] Mohanamurugan S, Sendilvelan S. Emission and Combustion Characteristics of Different Fuel In A HCCI Engine. International Journal of Automotive and Mechanical Engineering. 2011;3:279-92.

[8] Wang X, Xie H, Li L, Xie L, Chen T, Zhao H. Effect of the thermal stratification on SI-CAI hybrid combustion in a gasoline engine. Applied Thermal Engineering. 2013;61:451-60.

[9] Lee K, Min K. Study of a Stratification Effect on Engine Performance in Gasoline HCCI Combustion by Using the Multi-zone Method and Reduced Kinetic Mechanism. SAE Technical Paper; 2009.

[10] Wu C, Deng K, Wang Z. The effect of combustion chamber shape on cylinder flow and lean combustion process in a large bore spark-ignition CNG engine. Journal of the Energy Institute. 2016;89:240-7.

[11] Kakaee A-H, Nasiri-Toosi A, Partovi B, Paykani A. Effects of piston bowl geometry on combustion and emissions characteristics of a natural gas/diesel RCCI engine. Applied Thermal Engineering. 2016;102:1462-72.

[12] Hasan MM, Rahman MM. Homogeneous charge compression ignition combustion: Advantages over compression ignition combustion, challenges and solutions. Renewable and Sustainable Energy Reviews. 2016;57:282-91.

[13] Hamada KI, Rahman MM. An experimental study for performance and emissions of a small four-stroke SI engine for modern motorcycle. International Journal of Automotive and Mechanical Engineering. 2014;10:1852-65.

[14] Senzer EB. Piston ring pack design effects on production spark ignition engine oil consumption: a simulation analysis: Massachusetts Institute of Technology; 2007.

[15] Coskun G, Soyhan HS, Demir U, Turkcan A, Ozsezen AN, Canakci M. Influences of second injection variations on combustion and emissions of an HCCI-DI engine: Experiments and CFD modelling. Fuel. 2014;136:287-94.

[16] Izadi Najafabadi M, Abdul Aziz N. Homogeneous charge compression ignition combustion: challenges and proposed solutions. Journal of combustion. 2013;2013.

[17] Christensen M, Johansson B. Supercharged homogeneous charge compression ignition (HCCI) with exhaust gas recirculation and pilot fuel. SAE Technical Paper; 2000.

[18] Hunicz J. An experimental study of negative valve overlap injection effects and their impact on combustion in a gasoline HCCI engine. Fuel. 2014;117:236-50.

[19] Yao M, Zheng Z, Liu H. Progress and recent trends in homogeneous charge compression ignition (HCCI) engines. Progress in Energy and Combustion Science. 2009;35:398-437.

[20] Catapano F, Sementa P, Vaglieco BM. Air-fuel mixing and combustion behavior of gasoline-ethanol blends in a GDI wall-guided turbocharged multi-cylinder optical engine. Renewable Energy. 2016;96:319-32.

[21] Benajes J, Molina S, García A, Monsalve-Serrano J. Effects of direct injection timing and blending ratio on RCCI combustion with different low reactivity fuels. Energy Conversion and Management. 2015;99:193-209.

[22] Richter M, Engström J, Franke A, Aldén M, Hultqvist A, Johansson B. The influence of charge inhomogeneity on the HCCI combustion process. SAE Technical Paper; 2000.

[23] Bedoya ID, Saxena S, Cadavid FJ, Dibble RW, Wissink M. Experimental study of biogas combustion in an HCCI engine for power generation with high indicated 
efficiency and ultra-low NOx emissions. Energy Conversion and Management. 2012;53:154-62.

[24] Canakci M. Combustion characteristics of a DI-HCCI gasoline engine running at different boost pressures. Fuel. 2012;96:546-55.

[25] Ghorbanpour M, Rasekhi R. A parametric investigation of HCCI combustion to reduce emissions and improve efficiency using a CFD model approach. Fuel. 2013;106:157-65.

[26] Supeni E, Yusaf T, Wandel AP, Buttsworth DR, Noor M. Experimental and modeling investigation of the performance characteristics on diesel HCCI with hydrogen additive-a review. National Conference in Mechanical Engineering Research and Postgraduate Studies, Kuantan, Pahang, Malaysia2010. p. 580-96.

[27] Waldman J, Nitz D, Aroonsrisopon T, Foster DE, Iida M. Experimental investigation into the effects of direct fuel injection during the negative valve overlap period in an gasoline fueled HCCI engine. SAE Technical Paper; 2007.

[28] Wang Z, Shuai S-J, Wang J-X, Tian G-H. A computational study of direct injection gasoline HCCI engine with secondary injection. Fuel. 2006;85:1831-41.

[29] Ghafouri J, Shafee S, Maghbouli A. Investigation on effect of equivalence ratio and engine speed on homogeneous charge compression ignition combustion using chemistry based CFD code. Thermal Science. 2014;18:89-96.

[30] Rashid AK, Mansor A, Radzi M, Ghopa WAW, Harun Z, Mahmood WMFW. An experimental study of the performance and emissions of spark ignition gasoline engine. International Journal of Automotive and Mechanical Engineering. 2016;13(1):3540-54.

[31] Coleman GN. Homogeneous charge compression ignition (HCCI). 7th Diesel Engine Emissions Reduction (DEER) Workshop, Washington DC, August2001. p. 5-9.

[32] Hamada KI, Rahman M. An experimental study for performance and emissions of a small four-stroke SI engine for modern motorcycle. International Journal of Automotive and Mechanical Engineering. 2014;10:1852.

[33] Ghafoori M, Ghobadian B, Najafi G, Layeghi M, Rashidi A, Mamat R. Effect of nano-particles on the performance and emission of a diesel engine using biodieseldiesel blend. International Journal of Automotive and Mechanical Engineering. 2015;12:3097-3108.

[34] kumar Gugulothu S, Reddy KHC. Effect of Injection Timing \& Split Injection on Different Piston Bowl Configuration in a DI Diesel Engine. Procedia Engineering. 2015;127:924-31.

[35] Kim K-s, Shah P, Takiguchi M, Aoki S. Part 3: a study of friction and lubrication behavior for gasoline piston skirt profile concepts. SAE Technical Paper; 2009.

[36] Rahman M, Rosli B. Assessment of Fatigue Life Behaviour of Cylinder Block for Free Piston Engine Using Frequency Response Approach. Research Journal of Applied Sciences. 2008;3:32-43.

[37] Brain M. How car engines work. HowStuffWorks com. 2000;5.

[38] Pedersen TD, Schramm J. Reduction of HCCI combustion noise through piston crown design. International Powertrains, Fuels \& Lubricants Meeting: Session: Kinetically-Controlled CI Combustion (HCCI); 2010.

[39] Söderfjäll M, Herbst HM, Larsson R, Almqvist A. Influence on friction from piston ring design, cylinder liner roughness and lubricant properties. Tribology International. 2017;116:272-84. 
[40] Ravi K, Bhasker JP, Alexander J, Porpatham E. CFD study and experimental investigation of piston geometry induced in-cylinder charge motion on LPG fuelled lean burn spark ignition engine. Fuel. 2018;213:1-11.

[41] Fang J, Ma W, Biboulet N, Lubrecht A. Load carrying capacity and friction of an inclined parabolic-flat piston ring. Tribology International. 2017;113:286-90.

[42] Soni DK, Gupta R. Numerical analysis of flow dynamics for two piston bowl designs at different spray angles. Journal of Cleaner Production. 2017;149:72334.

[43] Tay KL, Yang W, Zhao F, Yu W, Mohan B. Numerical investigation on the combined effects of varying piston bowl geometries and ramp injection rateshapes on the combustion characteristics of a kerosene-diesel fueled direct injection compression ignition engine. Energy Conversion and Management. 2017;136:1-10.

[44] Shaver GM, Gerdes JC, Roelle MJ. Physics-based modeling and control of residual-affected HCCI engines. Journal of Dynamic Systems, Measurement, and Control. 2009;131:021002.

[45] Raj ARGS, Mallikarjuna JM, Ganesan V. Energy efficient piston configuration for effective air motion-A CFD study. Applied Energy. 2013;102:347-54.

[46] Xu T, Hwang S-J, Tang C-Y, Ejakov M, King M. An advanced and comprehensive CAE approach of piston dynamics studies for piston optimal and robust design. SAE International Journal of Engines. 2011;4:2087-99.

[47] Dakhore R, Gandhi NG, Gokhale N, Aghav Y, Kumar M, Hulwan DB. Effect of Piston Cavity Geometry on Combustion, Emission and Performance of a Medium Duty DI Diesel Engine. SAE Technical Paper; 2015.

[48] Gafoor CA, Gupta R. Numerical investigation of piston bowl geometry and swirl ratio on emission from diesel engines. Energy Conversion and Management. 2015;101:541-51.

[49] Vressner A, Hultqvist A, Johansson B. Study on combustion chamber geometry effects in an HCCI engine using high-speed cycle-resolved chemiluminescence imaging. SAE Technical Paper; 2007.

[50] Christensen M, Johansson B. The effect of in-cylinder flow and turbulence on HCCI operation. SAE Technical Paper; 2002.

[51] Aceves SM, Flowers DL, Martinez-Frias J, Espinosa-Loza F, Christensen M, Johansson B, et al. Analysis of the effect of geometry generated turbulence on HCCI combustion by multi-zone modeling. SAE Technical Paper; 2005.

[52] Zheng Z, Liu C, Tian X, Zhang X. Numerical study of the effect of piston top contour on GDI engine performance under catalyst heating mode. Fuel. 2015; 157:64-72.

[53] Cao L, Bhave A, Su H, Mosbach S, Kraft M, Dris A, et al. Influence of injection timing and piston bowl geometry on PCCI combustion and emissions. SAE International Journal of Engines. 2009;2:1019-33.

[54] Hyvönen J, Wilhelmsson C, Johansson B. The effect of displacement on airdiluted multi-cylinder HCCI engine performance. SAE Technical Paper; 2006.

[55] Kashdan JT, Docquier N, Bruneaux G. Mixture preparation and combustion via LIEF and LIF of combustion radicals in a direct-injection, HCCI diesel engine. SAE Technical Paper; 2004.

[56] Haraldsson G. Closed-loop combustion control of a multi cylinder HCCI engine using variable compression ratio and fast thermal management: Division of Combustion Engines, Lund Institute of Technology; 2005. 
[57] Larsson J. Development of a counter piston two stroke HCCI engine: Skolan för industriell teknik och management, Kungliga Tekniska högskolan; 2009.

[58] Zhang $\mathrm{Y}$, Zhao $\mathrm{H}$. Investigation of combustion, performance and emission characteristics of 2-stroke and 4-stroke spark ignition and CAI/HCCI operations in a DI gasoline. Applied Energy. 2014;130:244-55.

[59] Osborne RJ. Controlled auto-ignition processes in the gasoline engine: University of Brighton; 2010.

[60] Huang R, Yang H, Yeh C-N. In-cylinder flows of a motored four-stroke engine with flat-crown and slightly concave-crown pistons. Experimental Thermal and Fluid Science. 2008;32:1156-67.

[61] Zhang Y, Kung E, Haworth D. A PDF method for multidimensional modeling of HCCI engine combustion: effects of turbulence/chemistry interactions on ignition timing and emissions. Proceedings of the Combustion Institute. 2005;30:2763-71.

[62] HONG C, SONG L-q. Computer Aided Design and Optimization of Automobile Engine Piston Skirt Profile Curve [J]. Internal Combustion Engines. 2010;4:008.

[63] Meng X, Fang C, Xie Y. Transient tribodynamic model of piston skirt-liner systems with variable speed effects. Tribology International. 2016;94:640-51.

[64] Abu-Nada E, Al-Hinti I, Al-Sarkhi A, Akash B. Effect of piston friction on the performance of SI engine: a new thermodynamic approach. Journal of Engineering for Gas turbines and power. 2008;130:022802.

[65] Mahlia T, Saktisahdan T, Jannifar A, Hasan M, Matseelar H. A review of available methods and development on energy storage; technology update. Renewable and Sustainable Energy Reviews. 2014;33:532-45.

[66] Costa M, Sorge U, Allocca L. Increasing energy efficiency of a gasoline direct injection engine through optimal synchronization of single or double injection strategies. Energy Conversion and Management. 2012;60:77-86.

[67] Indrodia A, Chotai N, Ramani B. Investigation of different combustion chamber Geometry of diesel engine using CFD modelling of in cylinder flow for improving the performance of engine. 5th International and 26th All India Manufacturing Technology, Design and Research Conference, 2014;489-1-6.

[68] Bouazza M, Boucheta A, Becheri T, Benseddiq N. Thermal stability analysis of functionally graded plates using simple refined plate theory. International Journal of Automotive and Mechanical Engineering. 2017;14:4013-29.

[69] Güralp O, Hoffman M, Assanis DN, Filipi Z, Kuo T-W, Najt P, et al. Thermal characterization of combustion chamber deposits on the hcci engine piston and cylinder head using instantaneous temperature measurements. SAE Technical Paper No. 2009-01-0668.

[70] Lu Y, Zhang X, Xiang P, Dong D. Analysis of thermal temperature fields and thermal stress under steady temperature field of diesel engine piston. Applied Thermal Engineering. 2017;113:796-812.

[71] Mon TT, Mamat R, IAENG NK. Thermal analysis of SI Engine using simplified finite element model. Proceedings of the World Congress on Engineering; 2011. p. 6-8.

[72] Aceves SM, Flowers DL, Espinosa-Loza F, Martinez-Frias J, Dibble RW, Christensen M, et al. Piston-liner crevice geometry effect on HCCI combustion by multi-zone analysis. SAE Technical Paper No. 2002-01-2869.

[73] Hyvönen J, Haraldsson G, Johansson B. Operating range in a multi cylinder HCCI engine using variable compression ratio. SAE Technical Paper No. 2003-01-1829. 